Results: In this cohort of 90 patients, 71 (78.9\%) were women. Of the 90 patients, $19(21.1 \%)$ had no pharmacological prescription at all. Forty-nine patients $(54.4 \%)$ had one prescribed drug, $17(18.9 \%)$ had two drugs and $5(5.6 \%)$ had three drugs. Prescribed drugs and their frequencies are reported in Table 1.

Table 1. Prescribed drugs and frequencies.

\begin{tabular}{lc}
\hline \multicolumn{1}{c}{ Drug } & $\mathbf{n}(\%)$ \\
\hline No treatment & $19(21.1)$ \\
Celecoxib & $26(28.9)$ \\
Oxicams & $22(24.4)$ \\
Propionic acid derivatives & $6(6.7)$ \\
Phenyl Acetic acids & $5(5.6)$ \\
Acetaminophen & $15(16.7)$ \\
Tramadol & $12(13.3)$ \\
Steroids & $11(12.2)$ \\
Methotrexate & $1(1.1)$ \\
\hline
\end{tabular}

Conclusion: The most common group of drugs used for hand arthralgia in this cohort of patients was NSAID, and the most used of this group was celecoxib. Only in one patient, PCP prescribed disease-modifying anti-rheumatic drugs (DMARD) therapy, in this case was methotrexate. Almost $80 \%$ of the patients were prescribed with at least one drug without knowing the final diagnosis.

References:

[1] Warburton L, Hider SL, Mallen CD, Scott IC. Suspected very early inflammatory rheumatic diseases in primary care. Best Pract Res Clin Rheumatol. 2019;33(4):101419

[2] Calabrese L. Rheumatoid arthritis and primary care: The case for early diagnosis and treatment. The Journal of the American Osteopathic Association. 1999;99(6):313.

Disclosure of Interests: None declared

DOI: 10.1136/annrheumdis-2020-eular.4728

\section{AB1362-HPR COMMON PRACTICE IN DELIVERY OF INTRA- ARTICULAR THERAPIES IN RMDS BY HEALTH PROFESSIONALS: RESULTS FROM A EUROPEAN SURVEY}

J. De la Torre-Aboki ${ }^{1}$, I. Pitsillidou ${ }^{2}$, J. Uson Jaeger ${ }^{3}$, E. Naredo ${ }^{4}$, L. Terslev ${ }^{5}$, M. Boesen ${ }^{6}$, H. Pandit', I. Möller ${ }^{8}$, M. A. D'agostino ${ }^{9}$, W. U. Kampen ${ }^{10}$, T. O'neill ${ }^{11}$ M. Doherty ${ }^{12}$, F. Berenbaum ${ }^{13}$, V. Vardanyan ${ }^{14}$, E. Nikiphorou ${ }^{15}$, S. C. RodriguezGarcía $^{16}$, R. Castellanos-Moreira ${ }^{17}$, L. Carmona ${ }^{18} .{ }^{1}$ Hospital General Universitari d'Alacant, Alacant, Spain; ${ }^{2}$ Cyprus League Against Rheumatism, Nicosia, Cyprus; ${ }^{3}$ Hospital Universitario de Móstoles, Móstoles, Spain; ${ }^{4}$ Hospital Universitario Fundación Jiménez Díaz, Madrid, Spain; ${ }^{5}$ Rigshospitalet, København, Denmark; ${ }^{6}$ Bispebjerg and Frederiksberg Hospital, København, Denmark; ${ }^{7}$ University of Leeds, Leeds, United Kingdom; ${ }^{8}$ Institut Poal de Reumatologia, Barcelona, Spain; ${ }^{9}$ APHP-Université Paris-Saclay Versailles, Inserm, Boulogne-Billancourt, France; ${ }^{10}$ Rad. Allianz, Nuklearmedizin Spitalerhof, Hamburg, Germany; ${ }^{11}$ University of Manchester, Manchester, United Kingdom; ${ }^{12}$ University of Nottingham, Nottingham, United Kingdom; ${ }^{13} \mathrm{AP}$-HP Sorbonne Université, Inserm, Paris, France; ${ }^{14}$ Mikayelyan University Hospital, Yerevan, Armenia; ${ }^{15}$ King's College, London, United Kingdom;

${ }^{16}$ Hospital de La Princesa, Madrid, Spain; ${ }^{17}$ Hospital Clínic de Barcelona,

Barcelona, Spain; ${ }^{18}$ InMusc, Madrid, Spain

Background: Intra-articular therapies (IAT) are routinely used in rheumatic and musculoskeletal diseases (RMDs); however large variability exists regarding current practice of delivery amongst health professionals.

Objectives: To inquire about common practice aspects to inform the EULAR Taskforce for the IAT of arthropathies.

Methods: A steering committee prepared a 160 -item questionnaire based on the information needs of the Taskforce. The survey was disseminated via EULAR professional associations and social media and it was open to any health professional treating persons with RMDs, regardless of using IAT personally.

Results: The survey was answered by 186 health professionals from 26 countries, the large majority of whom $(77 \%)$ were rheumatologists, followed by nurses $(12 \%)$, general practitioners $(2 \%)$ and orthopaedic surgeons $(2 \%)$. The two collectives that perform IAT routinely are rheumatologists $(97 \%)$ and orthopaedic surgeons $(89 \%)$, with other professionals $<50 \%$. Specific training was compulsory for $32 \%$. The most frequent indication for IAT is inflammatory arthritis $(76 \%)$, followed by osteoarthritis $(74 \%)$, crystal arthritis $(71 \%)$ and bursitis $(70 \%)$; and all joints are injected, with knee $(78 \%)$ and shoulder $(70 \%)$ being the most frequent. When questioned about specific contexts, such as pre-surgical, diabetic or hypertensive patients, variability among respondents was evident, with around 30 to $69 \%$ of professionals considering it acceptable to inject glucocorticoids (GC), while in others there was less variability (prosthetic or septic joints, $<1 \%$ ). GCs are the most used compounds, followed by hyaluronic acid and saline/dry puncture. Only $66(36 \%)$ use ultrasound to guide IAT. In their opinion, to be accurately in the joint is moderately to largely important for large joints (80\%) and very important in small joints. The maximum number of injections to perform safely in the same joint within one year was " 2 to 3 " for $65 \%$ ( $2 \%$ thought there is "No limit"). The majority reported that they informed patients about side-effects $(73 \%)$, benefits $(72 \%)$, and the nature of the procedure $(72 \%)$, and less frequently about other aspects; with $10 \%$ obtaining written consent and $56 \%$ oral consent (mandatory only for $32 \%$ ). Other questions help to understand the setting and procedures followed, including use of local anaesthetics and care after injection. Conclusion: Although often performed in clinical practice for RMDs, there is apparent variability in several elements related to delivery of this treatment. This information, together with patient input, will help design current recommendations where research evidence is not available.

Acknowledgments: Eular Taskforce grant CL109

Disclosure of Interests: Jenny de la Torre-Aboki: None declared, IRENE Pitsillidou: None declared, Jacqueline Uson Jaeger: None declared, Esperanza Naredo: None declared, Lene Terslev: None declared, Mikael Boesen Consultant of: AbbVie, AstraZeneca, Eli Lilly, Esaote, Glenmark, Novartis, Pfizer, UCB, Paid instructor for: IAG Image Analysis Group, AbbVie, Eli Lilly, AstraZeneca, esaote, Glenmark, Novartis, Pfizer, UCB (scientific advisor)., Speakers bureau: Eli Lilly, Esaote, Novartis, Pfizer, UCB, Hemant Pandit Grant/research support from: Glaxo Smith Kline (GSK) for work on Diclofenac Gel, Speakers bureau: Bristol Myers Squibb for teaching their employees about hip and knee replacement, Ingrid Möller: None declared, Maria Antonietta D'Agostino Consultant of: AbbVie, BMS, Novartis, and Roche, Speakers bureau: AbbVie, BMS, Novartis, and Roche, Willm Uwe Kampen: None declared, Terence O'Neill: None declared, Michael Doherty Grant/research support from: AstraZeneca funded the Nottingham Sons of Gout study, Consultant of: Advisory borads on gout for Grunenthal and Mallinckrodt, Francis Berenbaum Grant/research support from: TRB Chemedica (through institution), MSD (through institution), Pfizer (through institution), Consultant of: Novartis, MSD, Pfizer, Lilly, UCB, Abbvie, Roche, Servier, Sanofi-Aventis, Flexion Therapeutics, Expanscience, GSK, Biogen, Nordic, Sandoz, Regeneron, Gilead, Bone Therapeutics, Regulaxis, Peptinov, 4P Pharma, Paid instructor for: Sandoz, Speakers bureau: Novartis, MSD, Pfizer, Lilly, UCB, Abbvie, Roche, Servier, Sanofi-Aventis, Flexion Therapeutics, Expanscience, GSK, Biogen, Nordic, Sandoz, Regeneron, Gilead, Sandoz, Valentina Vardanyan: None declared, Elena Nikiphorou: None declared, Sebastian C Rodriguez-García Speakers bureau Novartis Farmaceutica, S.A., Merck Sharp \& Dohme España, S.A., Sanofi Aventis, UCB Pharma, Raul Castellanos-Moreira: None declared, Loreto Carmona Grant research support from: Novartis Farmaceutica, SA, Pfizer, S.L.U., Merck Sharp \& Dohme España, S.A., Roche Farma, S.A, Sanofi Aventis, AbbVie Spain, S.L.U., and Laboratorios Gebro Pharma, SA (All trhough institution)

DOI: 10.1136/annrheumdis-2020-eular.96

\section{AB1363-HPR EVALUATION OF SELECTION CRITERIA OF CLINICIANS IN THE TREATMENT OF OSTEOPOROSIS, OSTREQ RESEARCH IN TURKEY}

\section{E. G. Kahraman ${ }^{1}$, S. Akar ${ }^{1}$, B. Ö. Pamuk' ${ }^{1}{ }^{1}$ Izmir Katip Çelebi Üniversitesi} Atatürk Eğitim ve Araştırma Hastanesi, Izmir, Turkey

Background: Osteoporosis is a disease with increasing prevalence in the aging and growing world population and its insidious progression and lack of findings without fracture cause certain difficulties in the diagnosis and treatment of this disease. There are many medical and paramedical treatment options for osteoporosis, and clinicians make these treatment decisions with many factors in mind. Objectives: We wanted to evaluate the importance of these factors for clinicians through a questionnaire. This 17-question questionnaire aimed to investigate the factors that clinicians consider in the planning of osteoporosis treatment and the effect of these factors on treatment planning. We made the Turkish version of the OSTEQ questionnaire in this study which factors clinicians in planning treatment for osteoporosis in Turkey we aimed to investigate that take into consideration.

Methods: OSTREQ questionnaire developed by Makraz et al. are used in this research. In this survey, which consists of 8 sections (health care system, patients' preferences regarding regimen's administration, usage, cost, severity of disease, treatment efficacy, safety profile and pharmaceutical industry) and 17 questions, the participants were asked to evaluate their answers with 5 different scales: Absolutely Preventive, Partially Preventive, Neither Preventive or Encouraging, Partially Encouraging, Absolutely Encouraging.

Clinicians of Rheumatology, Physical Therapy and Rehabilitation, Endocrinology and Metabolic Diseases participated in our study. The questionnaires were filled in by e-mail or by inviting the participants to the our university or by going to the clinics where the clinicians were working

Results: In our study 37 (21.8\%) were endocrinology, 49 (28.8\%) were rheumatology and $84(49.4 \%)$ were physical therapy and rehabilitation specialists. The overall Cronbach alpha coefficient of the questionnaire was found to be 0.855 . No material was found to significantly increase the internal reliability coefficient if deleted. As a result of $t$-test in $27 \%$ lower and upper groups to measure the discriminative powe of the items, it was seen that all items made a significant difference in the lowe and upper groups, which were formed according to the total score of 27 people. Confirmatory factor analysis and internal reliability results did not require removal of 
the substance, so the substance was not removed. When the responses of the specialist physicians participating in our study to the osteoporosis preference criteria questionnaire were examined according to their specialty, no statistically significant difference was found between specialty branches but only significant difference was found in health system and cost subscale according to branches $(p=0.013)$. Posthoc test (LSD) was used to find out the group that made a significant difference in health system and cost sub-factor. higher scores $(p=0.034)$.

Conclusion: We developed and validated a general osteoporosis treatment questionnaire that could provide assessment of the criteria that physicians take into consideration when they decide to implement a regimen for osteoporosis. This tool could assist health care systems and pharmaceutical companies understand which parameters drive physicians' choices regarding the treatment of osteoporosis.

References:

[1] P. Makras, A. Galanos, S. Rizou, A. D. Anastasilakis, and G. P. Lyritis, "Development and validation of an osteoporosis treatment questionnaire (OSTREQ) evaluating physicians' criteria in the choice of treatment," Hormones, vol. 15, no. 3, pp. 413-422, Jul. 2016.

[2] S. Tuzun et al., "Incidence of hip fracture and prevalence of osteoporosis in Turkey: The FRACTURK study," Osteoporos. Int., vol. 23, no. 3, pp. 949-955, Mar. 2012

Disclosure of Interests: None declared

DOI: 10.1136/annrheumdis-2020-eular.4473

\section{AB1364-HPR IS ADHERENCE TO TREATMENT RELATED TO THE EFFECTIVENESS OF ANTI-TNFS IN PATIENTS WITH RHEUMATOID ARTHRITIS? - ANALYSIS OF A REAL- WORLD COHORT}

P. Osorio $^{1}$, L. Villarreal ${ }^{1}$, M. Cabrera ${ }^{2}$, O. Valencia ${ }^{2}$, P. Santos-Moreno ${ }^{3}$.

${ }^{1}$ Biomab - Center for Rheumatoid Arthritis, Psychology, Bogota, Colombia;

${ }^{2}$ Biomab - Center for Rheumatoid Arthritis, Data Administration, Bogota,

Colombia; ${ }^{3}$ Biomab - Center for Rheumatoid Arthritis, Rheumatology, Bogota, Colombia

Background: Several medicines are prescribed for chronic disease management of rheumatoid arthritis (RA) including biologics; however, adherence to long-term therapy remains poor because many causes; the latter results in worsening clinical results.

Objectives: To analyze the relationship between adherence to treatment and the achievement of remission or low disease activity in patients with RA treated with three anti-TNF molecules of subcutaneous use.

Methods: In patients treated with 3 subcutaneous anti-TNFs, with at least one year of follow-up previously, adherence was measured with Compliance Questionnaire for Rheumatology (CQR19) applied by psychologist; the CQR19 is a 19 item, self-administered questionnaire that was developed with the aim of correctly identify rheumatology patients that were classified as "low" adherers (taking $<80 \%$ of their medication correctly) and defining as high adhesion a result greater than $80 \%$; adherence also was measured with medication possession rate (MPR) and attendance to scheduled consultations with the interdisciplinary team in each period measured. The effectiveness by DAS28, HAQ and the other measurements were made in three periods: at baseline (BL), 6 months (M6) and 12 months (M12). A Pearson correlation was made between the number of patients in remission and low disease activity by type of molecule and period, with adherence criteria.

Results: 112 patients diagnosed with RA were included, $34.8 \%(39 / 112)$ treated with adalimumab, 38.4\% (43/112) etanercept and $26.8 \%(30 / 112)$ golimumab; The results of CQR19 at BL, M6 and M12 were greater than $80 \%$, with no statistically significant differences between the three molecules. The MPR was higher than $80 \%$ in the three periods, being very similar between the three molecules, but in M12 period the difference in MPR between adalimumab $86 \%$ and golimumab $92.1 \%$ was statistically significant ( $p<0.005$ ), for etanercept it was of $90 \%$. Regarding to DAS28 and HAQ, there were no differences between the biologics analyzed; However, the highest percentage of patients with low disease activity and remission had a higher correlation with attendance to the consultations scheduled in the interdisciplinary RA care model $(r=0.78) p<0.005$ (see tables).

\begin{tabular}{lcccccc}
\hline CQR19 & \multicolumn{7}{c}{ MPR } \\
\hline & BL & M6 & M12 & BL & M6 & M12 \\
\hline ADALIMUMAB & 89,7 & 89,3 & 90,1 & 98,5 & 90,5 & 86,1 \\
ETANERCEPT & 87,4 & 89,7 & 89,7 & 97,9 & 89,6 & 90,9 \\
GOLIMUMAB & 88,2 & 87,6 & 91,5 & 97,1 & 96,1 & 92,1 \\
\hline
\end{tabular}

No statistical differences in adherence between biologics were found depending on sex, type of concomitant conventional treatment for RA or presence of comorbidities.
RELATION BETWEEN Rem/LDA AND COMPLIANCE WITH APPOINTMENTS

\begin{tabular}{lccccc}
\hline & Rem & LDA & MDA & HDA & \\
\hline ADALIMUMAB & $63 \%$ & $60 \%$ & $53 \%$ & $29 \%$ & $\mathrm{P}<0,005$ \\
ETANERCEPT & $66 \%$ & $62 \%$ & $73 \%$ & - & - \\
GOLIMUMAB & $68 \%$ & $73 \%$ & $55 \%$ & - & $\mathrm{P}<0,005$ \\
\hline
\end{tabular}

Conclusion: There seems to be a higher MPR with the monthly golimumab compared to the biweekly adalimumab and weekly etanercept; however, it does not necessarily imply greater effectiveness. Longer term studies are needed to confirm if there is better adherence and clinical results with monthly anti-TNFs than to other dosing regimens. Patients with remission and low disease activity had greater assistance to scheduled consultations with the interdisciplinary group, regardless of the type of molecule used. This study confirms the relation between adherence to medications and care model with clinical results.

Disclosure of Interests: Paola Osorio: None declared, Laura Villarreal: None declared, Michael Cabrera: None declared, Omaira Valencia: None declared, Pedro Santos-Moreno Grant/research support from: I have received research grants from Abbvie, Biopas-UCB, Janssen, Novartis, Pfizer., Speakers bureau: I have been speaker for Abbvie, Biopas-UCB, Janssen, Lilly, Novartis, Pfizer, Roche, Sanofi. DOI: 10.1136/annrheumdis-2020-eular.4779

\section{AB1365-HPR FREQUENCY OF JOINT DAMAGE IN PATIENTS WITH ULCERATIVE COLITIS}

D. Tarasova ${ }^{1}$, L. Shilova ${ }^{1}$, E. Lutaya ${ }^{1}$, E. Korenskaya ${ }^{1}$, M. Koroleva ${ }^{1}$,

A. Feoktistova ${ }^{1}{ }^{1}$ Volgograd State Medical University, Volgograd, Russian Federation

Background: Ulcerative colitis (UC) is considered as a systemic autoimmune disease with lesions of the colon mucosa. The current of UC is often accompanied by different extra-intestinal manifestations. Their frequency, according to various studies, varies widely - from 25 to $60 \%$. It is a serious problem that affects the quality of life and the effectiveness of therapy [1, 2]. Rheumatological manifestations, in particular, damage to the joints and spine, are one of the extra-intestinal manifestations and they are of particular importance. To date, the relationship between UC and joint damage has not been fully studied. These diseases can occur independently in the body or have a common autoimmune or inflammatory nature. It is believed that having common pathogenetic mechanisms of development, UC and joint damage can be different clinical forms of the same disease.

Objectives: To evaluate the frequency of clinical manifestations of joint damage in patients with ulcerative colitis.

Methods: The study was conducted at the gastroenterological Department of the Hospital №25 (Russia, Volgograd). Archived data from the case histories of 69 patients with a confirmed diagnosis of ulcerative colitis were analyzed, including 58 men (30.4\%) with an average age of 33.4 years, and 38 women (69.5\%) with an average age of 37.6 years.

Results: Among 48 patients with UC, extra-intestinal manifestations were detected in $40(41.6 \%)$ patients. A total lesion of the large intestine was found in 20 patients $(20.8 \%)$, left-sided colitis in $14(14,6 \%)$, proctosigmoiditis in 6 $(6.25 \%)$. The diagnosis was made for the first time in 4 patients $(4.16 \%), 36$ patients $(37.5 \%)$ were admitted to the hospital again due to an exacerbation of the disease. Among the extra-intestinal manifestations, joint lesions prevailed: 20 patients $(20.8 \%)$ showed clinical signs of peripheral arthritis, spondyloarthritis was detected in 8 patients $(8.3 \%)$, and 6 patients $(6.25 \%)$ had symptoms of unilateral sacroiliitis. $4(4.16 \%)$ patients were diagnosed with nodular erythema. Primary sclerosing cholangitis was detected in two patients $(2.08 \%)$.

Conclusion: The development of extra-intestinal manifestations in UC is largely determined by the course of the disease and the length of the inflammatory process in the colon. More than a third of patients with UC revealed extra-intestinal manifestations, among which the most common signs of joint damage were present, which necessitates timely diagnosis of extra-intestinal manifestations and involvement of a rheumatologist in the management of this category of patients. References:

[1] Knyazev O. V. et al. Epidemiologi of inflammatory bowel disease. Yesterdey, today, tomorrow. Eksperimental'naya i Klinicheskaya Gastroenterologiya 2017; 139 (3): 4-12 (In Russ.)

[2] Sadygova G.G. Extraintestinal manifestations of inflammatory bowel diseases: arthropathy and arthritis. Ross z gastroenterol gepatol koloproktol 2016; 26(6):101-5 (In Russ.)

Disclosure of Interests: None declared

DOI: 10.1136/annrheumdis-2020-eular.2636 